\title{
How Distance to School and Study Hours after School Influence Students' Performance in Mathematics and English: A Comparative Analysis
}

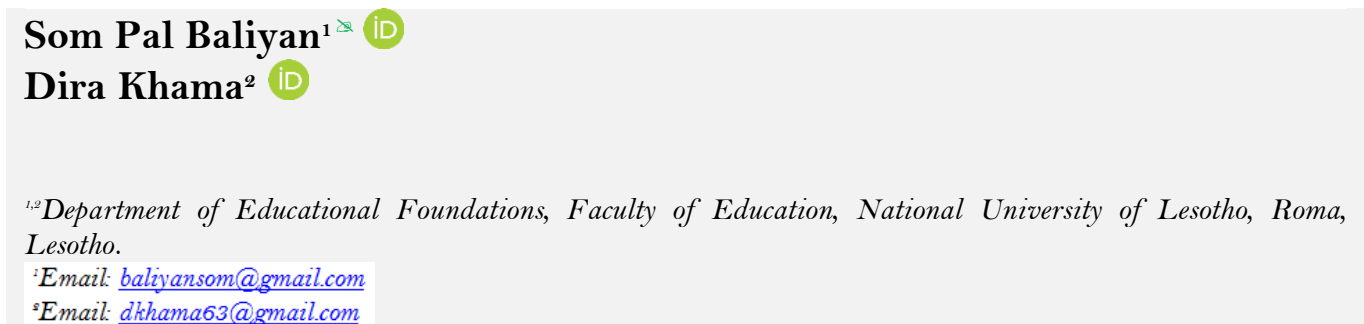

Abstract

Mathematics and English are essential subjects of the education system globally, as they provide skills for everyday human life. Mathematics and English are core subjects in the senior secondary education program in Botswana. The performance of students in Botswana in mathematics and English over the years has been poor. Most students travel long distances to school and have to return home every day. The distance to school and the hours after school for studying may contribute to the poor performance of students in these subjects. This quantitative study determined the influence of the distance to school and after school study hours on the performance of senior secondary students in mathematics and English in Botswana. Data were collected through a survey of a random sample of 168 students learning mathematics and English in senior secondary schools in Botswana. Findings of analyses of variance indicated that study hours after school and the distance to school have a significant influence on the performance of students in mathematics, whereas no influence was determined on student performance in English. Further, Post Hoc analysis determined that the long travelling distance and low number of hours of after school study had a sizeable adverse influence on student performance in mathematics. To improve student performance in mathematics, it was recommended that stakeholders should ensure that students stay closer to school and had better, more reliable transport. The former can be achieved by increasing the amount of hostel accommodation in schools.
Citation | Som Pal Baliyan; Dira Khama (2020). How Distance to School and Study Hours after School Influence Students' Performance in Mathematics and English: A Comparative Analysis. Journal of Education and e-Learning Research, 7(2): 209-2 17. History:

Received: 29 April 2020

Revised: 5 June 2020

Accepted: 7 July 2020

Published: 20 July 2020

Licensed: This work is licensed under a Creative Commons

Attribution 3.0 License $(\mathrm{cc}) \mathbf{E}$ )

Publisher: Asian Online Journal Publishing Group

\section{Contents}

\section{Introduction}

2. Review of Literature

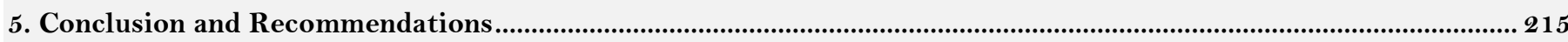

References...

Acknowledgement: Both authors contributed to the conception and design of the study.

Funding: This study received no specific financial support

Competing Interests: The authors declare that they have no conflict of interests.

Transparency: The authors confirm that the manuscript is an honest, accurate, and transparent account of the study was reported; that no vital study as planned have been explained.

Ethical: This study follows all ethical practices during writing. 


\section{Contribution of this paper to the literature}

This is the first empirical study comparing the influence of distance to school and study hours after school on the performance of students in senior secondary schools in Botswana. The findings of the study shall help in improving the poor performance of students in mathematics and English in the country. It was recommended to the stakeholders to ensure that students stay in close proximity of the schools; preferably in hostels in schools or ensure a reliable transport to school.

\section{Introduction}

Academic performance of students is one of the indicators of quality education, and this has been declining in Botswana (Government of Botswana, 2015; UNESCO, 2015). This decline has become a matter of grave concern to the nation (Bulawa, 2017). However, the government of Botswana has been working hard to facilitate improved outcomes for all learners by addressing several challenges of quality education in the country. These challenges include lack of qualified teachers, ineffective teachers, irrelevance of the curriculum, low morale among teachers, large classes, lack of teaching aids, declining enrolment, retention of students, negative attitude among students, high drop-out numbers, and lack of practical skills (MoESD Ministry of Education and Skills Development, 2015; Oketch, 2017). All these challenges contribute to poor academic performance and skill development among the students. Academic performance refers to the ability to grasp the essentials of a subject, which is reflected in the percentage marks obtained through valid and reliable testing methods. In this study, the performance of students refers to percentage marks with Grade C or higher (Botswana Examinations Council, 2016).

Mathematics and English education are considered the two most important subjects in the education system worldwide, as these are integral to every step we take in human life. Mathematics is a subject whereby understanding of the numbers is obtained in order to enhance numerical ability. English as a language subject equips students with skills in reading, writing, speaking, and communicating. It is thus implied that mathematical and English knowledge would be utilised in the acquisition of practical and applied skills in sustainable human life. Therefore, mathematical and English education are emphasised at all levels of education, from primary to tertiary levels. Mathematics and English are offered as core subjects in the government senior secondary schools in Botswana through the Botswana General Certificate of Secondary Education (BGCSE) curriculum. Tertiary institutions in the South African Development Community (SADC) region normally require pass or credits in senior secondary mathematics and English as entry requirements. While reviewing examination results over the years, it is clear that the performance of students in mathematics and English has been poor when compared with other subjects (Botswana Examinations Council, 2010, 2015, 2019). The academic performance of students in senior secondary mathematics and English has not only been poor but has also continually declining or stagnant for some years. The students' performance in senior secondary mathematics deteriorated from $60.18 \%$ to $40.52 \%$ between 2007 and 2011 for Grade C and higher (Botswana Examinations Council, 2011). Most recently, in 2018, out of the total grades awarded in mathematics, only $28.41 \%$ were Grade C or higher. This is lower than the percentage of these grades obtained in 2010 (29.34\%) (Botswana Examinations Council, 2019). The performance of students in mathematics reveals an overwhelming downturn which is worth noting, beyond reasonable doubt (Nyroos, Jonsson, Korhonen, \& Eklöf, 2015). The performance of students in English has almost the same, stagnant trend in Botswana. Table 1 reflects the declining or stagnant trends in student performance in mathematics and English in senior secondary schools in Botswana.

\begin{tabular}{c|c|c}
\multicolumn{2}{|c|}{ Table-1. Declining trend in students' performance in the senior secondary mathematics and English in Botswana. } \\
\hline Year & Performance (\% of Grade 'C' or better) & English \\
\hline 2010 & Mathematics & 17.31 \\
\hline 2012 & 29.34 & 15.37 \\
\hline 2014 & 27.61 & 17.07 \\
\hline 2016 & 22.64 & 24.42 \\
\hline 2018 & 27.47 & 23.11 \\
\hline
\end{tabular}

Poor performance, particularly in mathematics, continues to be a concern among the students, teachers, and other stakeholders. There may be several factors affecting performance, including demographic factors such as gender, location of residence, teacher attitudes, teacher qualifications, parents' education, distance to school, and socio-economic status. Numerous factors have been identified by researchers for the inconsequential performance by students, some of which include a shortage of qualified mathematics teachers, and poor facilities, equipment and instructional materials for effective teaching (Avong, 2013; Umameh, 2011; Yemi \& Adeshina, 2013). Evidence from research has also shown that long distances travelled to school are among the major reasons why students perform poorly and eventually drop out of school (Arubayi, 2005; Ebinum, Akamagune, \& Ugbong, 2017). A number of studies have been conducted on poor performance, particularly in mathematics, in developed countries, but there has been scant literature on this problem in developing countries, particularly in Botswana. Therefore, this study was an attempt to determine the influences of the distance to school and study hours after school on the performance of senior secondary students in mathematics and English in Botswana. The study was useful to the stakeholders, including students, parents, school management, and policymakers as the findings provided important information about the aforementioned influences which should help in improving student performance in the country in these two subjects.

\subsection{Aims and objectives}

This study was an attempt to determine the influence of the distance to school and study hours after school on the performance of senior secondary students in mathematics and English in Botswana. The specific objectives of the study were:

1. To determine the influence of distance to school on the performance of students in mathematics and English. 
2. To determine the influence of study hours after school on the performance of students in mathematics and English.

The objectives of the study were translated into the following questions:

1. To what extent does distance to school influence the performance of students in mathematics and English.

2. To what extent do study hours after school influence the performance of students in mathematics and English.

To answer the research questions, the following null hypotheses were formulated:

$H_{o r}$ : The distance to school has no significant influence on the performance of students in mathematics and English.

$H_{o 2:}$ The study hours after school have no significant influence on the performance of students in mathematics and English.

\section{Review of literature}

The distance that students travel from home to school has been an issue of interest to numerous studies over the years. Unanimously, these studies confirm that commuting students are affected to some extent, both healthwise and educationally. The categorisation of travel modes for student commutes in different parts of the world is in two types; active and passive modes of travel from home to school. According to Easton and Ferrari (2015), a passive or non-active mode of travel is characterised by the use of motorised forms of transport such as cars, buses, minibuses, taxis, and trains, while active modes of transport consist of using bicycles, skateboards, and simply walking. However, the passive or non-active mode is not entirely passive when students walk to and from a terminal or station to catch a bus, minibus, taxi, or train.

International literature on active commuting to school, particularly in advanced countries like the United States, is growing because of the potential benefits of active commuting as a form of physical exercise (Easton \& Ferrari, 2015; Hinchson et al., 2014; Vuri, 2007). Although there are some differences amongst developed countries in the use of active and passive modes of transport; the conditions and situations are distinct between the advanced and developing countries. The effects of active and passive modes of transports are far less hazardous when compared with the developing countries where students walk long distances for hours, sometimes in the dangerous and difficult terrain of mountains, rivers, and forests. In most advanced countries, passive or motorised transport is modern, relatively safe, and affordable, in sharp contrast with the poor, scarce, or non-existence of safe motorised transport in developing countries (The New Times, 2016). Long walking distance is a common phenomenon that students endure, and it poses psychological and physical repercussions and health hazards. Studies have found that community students suffer from fatigue and low morale that may lead to dropping out of school or poor concentration in class after spending long hours on the road to get there, and home again(Marique, Dujardin, Teller, \& Reiter, 2013). Waking up early and returning home late severely limit students' time for private studying. Further, commuting distance has a profound effect on the sleep patterns of adolescent school students (Pradhan \& Sinha, 2017).

The literature further confirms the effects of distance to school on students' performance (Easton \& Ferrari, 2015; The New Times, 2016; Vuri, 2007). Thapa (2015) and Getachew (2018) reported that distance to school has a significant influence on students' performance. Creswell and Creswell (2017) determined that the distance from school has a negative influence on the academic performance of students. Idowu (2016) found a positive correlation between distance from students' home to the school and students' performance in mathematics which further determined that there is a significant effect on performance in mathematics of those who travel a long distance to school. Arubayi (2005) also reported similar findings that there was a correlation between the students' performance and distance from home to school. Mhiliwa (2015) found that a long walking-distance to school affected students' performance as compared with those who stay within a short distance of the school. Ebinum et al. (2017) revealed that there is a significant relationship between the distance lived from school and the academic achievement of male students, while no significant relationship between school distance and academic achievement was determined for the female students. Falch, Lujala, and Strom (2011). He and Giuliano (2018) declared that distance to education institutions affects participation in education and later outcomes, wherein the increase in real travel time from a student's home to the school decreases the probability of graduating on time. Contradicting this conclusion, Camello (2014) also determined no significant difference in the student's performance when they were grouped according to the distance of their school from their place of residence.

Distance to school may influence student performance through a variety of factors associated with longdistance travel to and from school (Thomas, 2016). Students travelling substantial distances to school would be exposed to longer time spent in transit, which may detract from the time they can spend on homework or preparing for the next day of school (Andre-Bechely, 2007). Nelson, Misra, Sype, and Mackie (2016) reported that students who live further away from a school find it difficult to complete outside-school tasks requested by their teachers. Waswa (2015) found that long distances hinder girls from continuing school, and this contributes to a failure to complete their class and homework. Moyo (2013) stated that walking over long distances to and from school might lead to arriving at school late and getting back home late after school. It was also indicated that longer walking distances cause fatigue and hunger, leading students to drowsiness during learning sessions. Walking over long distances to school disadvantages students in arriving at school late having already lost a considerable amount of energy, leading to poor concentration on their school work. Mhiliwa (2015) determined that longer distances travelled made students reach schools tired and unprepared for the classroom and their private studies. Consequently, poor preparation in school sessions and private studies impacted students and caused failures in their national examinations. Mhiliwa (2015) indicated that students who walk or travel further to reach school could be tempted by distractions on the way to or from school, particularly students from poor families who cannot afford to hire transport to reach schools earlier. Travelling or walking long distances to school also distracts students in a way that facilitates pregnancies in girls and juvenile behaviours in boys. Further, he reported that theft of students' belongings on their journeys is common, which disturbs the students mentally and also influences their performance (Mhiliwa, 2015). Onderi, Kiplangat, and Awino (2014) indicated that walking long distances to school meant students reached their destination with empty stomachs, and were often late, which reflected adversely on their academic performance. Taiwo (2019) determined that walking long distances to and 
from school on a daily basis has a negative impact on students' academic performance as it could promote absenteeism and fatigue leading to lack of concentration and interest in school activities, with indirect negative results of delinquency and lack of discipline.

Whether a distant school is chosen or not is determined by parents' school preferences and their willingness to travel (He \& Giuliano, 2018). In England, one of the most important factors in parents' first choice of school is proximity to home, where $25.56 \%$ of parents place this at the top of their priorities in school selection. (Burgess, Greaves, Vignoles, \& Wilson, 2009). Akhtar (2012) advised parents to enrol their children in schools nearer their home because a longer travel distance negatively affects the achievements of their children. Mandic et al. (2017) found that a shorter distance to school and the importance of a school's proximity to home were associated with enrolment in the closest secondary school. Therefore, it was also advised that the government should ensure that more schools are built to reduce the distance students have to travel to get an education. Idowu (2016) suggested that the government should start considering providing school buses for students to reduce the time they take travelling to and from school

Distance to school and study hours after schools are negatively correlated, and both of these factors influence the performance of students. Several recent studies have found that study hours have a positive influence on the academic performance of students (Hallo, Tixi Torres, Piñas, \& Zhining, 2020; Piza, Alexis, Galarza, Barahona, \& Nivela, 2019; Rodríguez Tapia, Caguanco Almeida, Portilla, \& Coca Freire, 2019) and Silva, Hidalgo, Garcés, and Riofrio (2019); Ali, Kiani, and Ahmed (2018) and Nonis and Hudson (2010). Conversely, Ng, Zakaria, Lai, and Confessore (2016) uncovered a negative and significant correlation between time spent reading and academic achievement, whereas a positive and substantial correlation between time spent studying and academic achievement was revealed. Further, it was indicated that the possible reason for this outcome is that the school examinations mainly test mainly a student's knowledge of their academic subjects. Thus the reading materials have less impact on their academic achievement. A similar finding was reported by Zahyah (2008), who found that reading hours did not correlate with the academic achievement of students. Thus, empirical research investigating the relationship between study hours and student performance has delivered mixed results (Krohn \& O'Connor, 2005; Lahmers \& Zulauf, 2000; Ng et al., 2016; Nonis \& Hudson, 2010).

To date, the relationship between distance to school, study hours after school, and student performance remains unclear and under-researched (Andre-Bechely, 2007; Ledwith, 2009; Thomas, 2016; Warrington, 2005). It is uncertain how travelling distances to school for one's education may impact a student's achievement (Andersson, Malmberg, \& Osth, 2012; Ledwith, 2009; Wells, Warner, \& Grzesikowski, 2013). Further, there is no subjectspecific study on the influence of travelling distance and study hours after school on students' performance in Botswana. Therefore, this study was conducted to determine the influence of the distance to school and study hours after school on the performance of senior secondary students in mathematics and English in Botswana.

\section{Methodology}

This quantitative study adopted a positivism paradigm as the best solution because the researcher was interested in quantifying the data (Creswell \& Creswell, 2017). Further, the outcomes of positivism are exploratory, and facts are uncovered from reality. This study is to determine the influence of distance to school and study hours on students' performance. A correlational research design was employed. This design was deemed appropriate as it allows the measurement of two or more variables and their relationship. The method helped in the attempt to expose the relationship to and influence of distance to school and study hours after school on the performance of students in senior secondary mathematics and English. Distance to school and study hours after school were considered as independent variables, and the performance of students was treated as the dependent variable.

The population of the study was the final year students in senior secondary schools in Botswana studying mathematics and English. A sample of 168 students was selected through a random sampling method. A survey design was employed for data collection. Data were collected using a pre-structured, valid, and reliable questionnaire. The questionnaire contained two sections; section one provided information on the demographic variables of distance to school and, study hours after school, section two focused on the performance of the student in mathematics and English which was considered as measured by the examination marks in mathematics and English. Data were collected in two phases. In the first phase, the questionnaires were given to the sampled students to provide information on section one of the questionnaire. In the second phase of data collection, the examination marks of sampled students in mathematics and English were collected from the school records. Oneway analysis of variance was performed for analysing data using SPSS Software Ver. 23.

\section{Results and discussion}

\subsection{Participant demographic information}

The demographic information of the respondents is presented in Table 2, which indicates that a total of 168 students, 80 males and 88 females, participated in this study. $36.3 \%$ of students obtained less than $49 \%$ marks in mathematics, while in English only $14.3 \%$ of students obtained less than $49 \%$ marks. Further, $24.4 \%$ and $32.1 \%$ of students achieved marks over $70 \%$ in mathematics and English, respectively. The majority of students (approximately 59\%) travelled to school for less than eight kilometres per day, and only $15.5 \%$ of students travelled for more than 16 kilometres per day. The same percentage of students (31.5\%) studied at home for more than 16 hours and less than eight hours per week, while $15.5 \%$ and $58.9 \%$ of students respectively travelled over $16 \mathrm{~km}$ and less than eight $\mathrm{km}$ to school every day. The data on travelling distance to school and study hours after school indicated that whether students travelled more or fewer kilometres to school, their study hours remained the same. Thus the travelling distance to school does not influence study hours after school. 
Table-2. Demographic characteristics of the participant students $(\mathrm{n}=168)$.

\begin{tabular}{l|c|cc}
\hline \multicolumn{1}{c}{ Characteristics } & Levels & f & \% \\
\hline Gender & Male & 80 & 47.6 \\
& Female & 88 & 52.4 \\
& Total & 168 & 100.0 \\
\hline \% Marks obtained in & $\geq 70$ & 41 & 24.4 \\
mathematics & $50-69$ & 66 & 39.3 \\
& $\leq 49$ & 61 & 36.3 \\
\hline Marks obtained in & Total & 168 & 100.0 \\
English & $\geq 70$ & 54 & 32.1 \\
& $50-69$ & 90 & 53.6 \\
& $\leq 49$ & 24 & 14.3 \\
Study hours after school & Total & 168 & 100.0 \\
per week & $\geq 16$ & 53 & 31.5 \\
& $9-15$ & 62 & 37.0 \\
& $\leq 8$ & 53 & 31.5 \\
Travel distance to school & Total & 168 & 100.0 \\
km/day & $\geq 16$ & 26 & 15.5 \\
& $9-15$ & 43 & 25.6 \\
\hline
\end{tabular}

\subsection{Influence of distance to school on students' performance in mathematics}

A one-way Analysis of Variance (ANOVA) was used to determine the influence of distance to school on the students' performance, whereby distance to school and performance of students were considered as independent and dependent variables, respectively. Means and standard deviations of the (ANOVA) of the influence of distance to school on students' performance in mathematics are shown in Table 3.

Table-3. Means and standard deviations of analysis of variance of influence of distance to school on students' performance in mathematics.

\begin{tabular}{c|c|c|c}
\hline Level of distance & $\mathbf{n}$ & Mean & SD \\
\hline$\geq 16$ & 26 & 52.47 & 20.27 \\
\hline $9-15$ & 43 & 55.11 & 17.62 \\
\hline$\leq 8$ & 99 & 62.19 & 17.05 \\
\hline Total & 168 & 54.65 & 19.35 \\
\hline
\end{tabular}

Table 3 indicates that between the three levels of distance to school, the longer distance had the lowest mean performance $(\overline{\mathrm{x}}=52.47)$, followed by the medium distance $(\overline{\mathrm{x}}=55.11)$. The shorter distance to school had the highest mean performance in mathematics $(\overline{\mathrm{x}}=62.19)$. Thus, there is a negative relationship between the distance to school and the performance of students in mathematics. In order to discover if the differences in the mean were statistically significant or not, a one-way ANOVA was performed.

The test for normality, examining standardised skewness and the Shapiro-Wilks tests, indicated that the data were normally distributed. Additionally, homogeneity of variances was not significant, Levene's $F(2,753)=2.777$, $\mathrm{p}=.063$, indicating that the assumption underlying the application of the ANOVA was met. The results of the ANOVA of the influence of distance to school on students' performance in mathematics are presented in Table 4.

Table-4. Analysis of variance of influence of distance to school on students' performance in mathematics.

\begin{tabular}{c|c|c|c|c|c}
\hline Level of distance & SS & df & MS & F & p \\
\hline Between & 1956.832 & 2 & 978.416 & 2.665 & .043 \\
\hline Within & 60577.144 & 165 & 367.134 & & \\
\hline Total & 62533.976 & 167 & & & \\
\hline
\end{tabular}

Table 4 reflected that the differences in the means of the performance of students in mathematics were statistically significant $\mathrm{F}(2,165)=2.665, \mathrm{p}=.043)$. It interpreted that the distance to school had a significant influence on student performance in mathematics. This discovery is similar to the findings of Thapa (2015); Easton and Ferrari (2015) and Getachew (2018) who determined that the distance to school has a significant influence on student performance.

Post Hoc comparisons using Tukey procedures were used to determine which pair of the levels of distance means differed. The results of the Post Hoc test are presented in Table 5.

Table-5. Post Hoc test results of the influence of distance to school on students' performance in mathematics.

\begin{tabular}{c|c|c|c|c}
\hline \multicolumn{2}{|c|}{ Table-5. Post Hoc test results of the influence of distance to school on students' performance in mathematics. } \\
\hline Level of distance & Mean & \multicolumn{3}{|c}{ Mean Differences } \\
\hline High & & High & Medium & Low \\
\hline Medium & 52.47 & $-\overline{6}$ & \\
\hline Low & 55.11 & 2.641 & - & - \\
\hline Note: * $p<.05$. & 62.19 & $9.717^{*}$ & 7.076 & - \\
\hline
\end{tabular}

Table 5 indicated that only the students with short (low) and long (high) distances to school had significant differences in their performances in mathematics. There is a higher difference in the performance of students in mathematics who travel longer distances than those who travel shorter distances (9.717). This finding translates that the higher the travelling distances, the lower the performance of students in mathematics. Therefore, there is a negative influence of travelling distances on student performance in mathematics. The findings are similar to 
Pradhan and Sinha (2017); Idowu (2016) and Mhiliwa (2015) who determined that the distance from school has a negative influence on the academic performance of students, and students who travel a long distance to school perform poorly when compared with those who stay within the school or at closer locations.

Literature shows that commuting students suffer from fatigue as well as loss of concentration (Moyo, 2013; Taiwo, 2019) and lack of sleeping time (Pradhan \& Sinha, 2017), due to long hours spent on the journey. Further, travelling long distances every day does not allow students time to attend to their studies at home (Nelson et al., 2016), and therefore commuting students perform poorly in mathematics. Mathematics is a subject which requires learners to apply high levels of concentration and energy to acquire the necessary knowledge and mathematical skills and, thus, to perform better.

\subsection{Influence of distance to school on students' performance in English}

A one-way ANOVA was used to determine the influence of distance to school on performance in English. Means and standard deviations of the ANOVA of the influence of distance to school on students' performance in English are shown in Table 6.

\begin{tabular}{c|c|c|c}
\multicolumn{2}{c}{ Table-6. Means and standard deviations of analysis of variance of influence of distance to school on students' performance in English. } \\
\hline Level of distance & $\mathbf{n}$ & Mean & SD \\
\hline$\geq 16$ & 26 & 67.07 & 12.37 \\
\hline $9-15$ & 43 & 70.39 & 13.72 \\
\hline$\leq 8$ & 99 & 69.54 & 13.39 \\
\hline Total & 168 & 69.38 & 13.29 \\
\hline
\end{tabular}

Table 6 indicates that among the three levels of distance to school, a longer (high) distance had the lowest mean performance $(\overline{\mathrm{x}}=67.07)$, while the medium and low level of distances to school had similar means of performance (approximately $\bar{x}=70$ ), which were both higher than the performance mean of students travelling for longer distances. Thus, there is a negative relationship between the levels of distance to school and the performance of students in English. In order to find out if the differences in the mean are statistically significant or not, a one-way ANOVA was performed.

The results of the ANOVA of the influence of distance to school on students' performance in English are presented in Table 7. It was found that the differences in the means of performance in English were not statistically significant $\mathrm{F}(2,165)=.520, \mathrm{p}=.595)$. The interpretation is that distance to school had no significant influence on student performance in English. This result is similar to the findings of Camello (2014), who determined that the distance to school has no significant influence on students' performance.

\begin{tabular}{c|c|c|c|c|c}
\multicolumn{6}{c}{ Table-7. ANOVA of influence of distance to school on students' performance in English. } \\
\hline Level of distance & SS & df & MS & F & p \\
\hline Between & 184.948 & 2 & 92.474 & .520 & .595 \\
\hline Within & 29324.671 & 165 & 177.725 & & \\
\hline Total & 29509.619 & 167 & & & \\
\hline
\end{tabular}

\subsection{Influence of study hours after school on students' performance in mathematics}

A one-way ANOVA was used to determine the influence of study hours after school on students' performance, whereby study hours after school and the performance of students were treated as independent and dependent variables respectively. Means and standard deviations of the ANOVA of the influence of study hours after school on students' performance in mathematics are shown in Table 8. This indicates that among the three levels of study hours after school, the high level of study hours had the highest mean of students' performance $\left(\bar{x}^{-}=62.60\right)$ followed by the medium level of study hours $(\bar{x}=53.14)$. The low level of study hours had the lowest mean of students' performance in mathematics $(\bar{x}=48.47)$. Thus, there is a positive relationship between the levels of study hours after school and students' performance in Mathematics.

Table-8. Means and standard deviations of analysis of variance of influence of study hours after school on students' performance in mathematics.

\begin{tabular}{c|c|cc}
\hline Level of study hours & n & Mean & SD \\
\hline$\geq 16$ & 53 & 62.60 & 17.33 \\
\hline $9-15$ & 62 & 53.14 & 20.61 \\
\hline$\leq 8$ & 53 & 48.47 & 17.26 \\
\hline Total & 168 & 54.65 & 19.35 \\
\hline
\end{tabular}

In order to find out if the differences in the mean of students' performance are statistically significant or not, a one-way ANOVA was performed. The results of the ANOVA of the influence of study hours after school on the performance of students in mathematics are presented in Table 9. It was found that the differences in the means of performance were statistically significant; $\mathrm{F}(2,165)=7.98, \mathrm{p}=.000)$. The interpretation is that the study hours after school had a significant influence on the performance of students in mathematics, and this finding is supported by the findings of Ali et al. (2018).

Further, most of the higher-performing students prefer to study alone as they do not want any interruptions while learning (Al Shawwa et al., 2015), and such an environment for study can more easily be availed at home.

Post Hoc comparisons using Tukey procedures were used to determine which pair of the levels of study hours means differed. The results of the Post Hoc test are presented in Table 10, which indicates that the means of performance are significantly different between high and medium levels of study hours $(M=9.458)$, and between high and low levels of study hours $(M=14.13)$. It further indicates that the greater the difference in study hours, 
the greater the difference in performance Students who studied for fewer hours showed no significant difference in their performance in mathematics.

Table-9. ANOVA of influence of study hours after school on students' performance in mathematics.

\begin{tabular}{c|c|c|c|c|c}
\hline $\begin{array}{c}\text { Level of study } \\
\text { hours }\end{array}$ & SS & df & MS & F & p \\
\hline Between & 5516.396 & 2 & 2758.198 & 7.982 & .000 \\
\hline Within & 57017.580 & 165 & 345.561 & & \\
\hline Total & 62533.976 & 167 & & & \\
\hline
\end{tabular}

Table-10. Post Hoc test results of the influence of study hours after school on students' performance in mathematics.

\begin{tabular}{c|c|c|c|c}
\hline Level of Study Hours & Mean & \multicolumn{3}{|c}{ Mean Differences } \\
\hline & & High & Medium & Low \\
\hline High & 62.60 & - & & \\
\hline Medium & 53.14 & $9.458^{*}$ & - & \\
\hline Low & 48.47 & $14.132^{*}$ & 4.673 & - \\
\hline
\end{tabular}

Note: $* \mathrm{p}<.05$.

The finding reflected that a higher level of study hours after school ( $\geq 16$ hours) had a significantly greater influence on the students' performance in mathematics than the medium level of study hours. This result is supported by the findings of Barbarick and Ippolito (2003), who determined that more study hours have a significant positive influence on students' performance.

\subsection{Influence of study hours after school on students' performance in English}

A one-way ANOVA was used to determine the influence of study hours after school on the performance in English. Means and standard deviations of the ANOVA of the influence of study hours after school on students' performance in English in Table 11 indicate that among the three levels of study hours after school, the higher hours of study had the highest mean of students' performance $(\bar{x}=73.13)$, followed by the medium level of study hours $(\overline{\mathrm{x}}=68.71)$. The lower level of study hours had the lowest mean of students' performance in English $(\overline{\mathrm{x}}=$ 68.45). Thus, a positive relationship between the levels of study hours after school and the performance in English was determined. A similar finding was reported by Ali et al. (2018).

Table-11. Means and standard deviations of analysis of variance of influence of study hours after school on students' performance in English.

\begin{tabular}{c|c|c|c}
\hline Level of study hours & $\mathbf{n}$ & Mean & SD \\
\hline$\geq 16$ & 53 & 71.13 & 12.33 \\
\hline $9-15$ & 62 & 68.71 & 13.69 \\
\hline$\leq 8$ & 53 & 68.45 & 13.81 \\
\hline Total & 168 & 69.38 & 13.29 \\
\hline
\end{tabular}

In order to find out if the differences in the mean of students' performance were statistically significant or not, a one-way ANOVA was run. The results of the ANOVA of influence of study hours after school on the performance of students in English are presented in Table 12. It was found that the differences in the means of performance were not statistically significant $\mathrm{F}(2,165)=.675, \mathrm{p}=.511)$. It interpreted that the study hours after school had no significant influence on the performance of students in English. A similar finding was reported by Zahyah (2008).

Table-12. ANOVA of influence study hours after school on students' performance in English.

\begin{tabular}{c|c|c|c|c|c}
\hline Level of study hours & SS & df & MS & F & p \\
\hline Between & 239.434 & 2 & 119.717 & .675 & .511 \\
\hline Within & 29270.185 & 165 & 177.395 & & \\
\hline Total & 29509.619 & 167 & & & \\
\hline
\end{tabular}

Both subjects, mathematics and English, require substantial practice for learners to comprehend them and meet the required proficiency. Although English as a core subject needs plenty of practice, mathematics depends more on instruction in school, and comparatively, students engage more frequently in English than any other school subject, with the exception of teaching and learning of a vernacular language. Perhaps this may explain the difference between the two subjects. Additionally, mathematics is relatively technical and falls in the category of complex subjects which require much practice for a student to perform better. Further, there is a correlation between the distance to school and study hours after school. The longer the distance to school, the more the hours of study after school are reduced as the students take time to travel to school and back to home.

\section{Conclusion and recommendations}

The findings of the study concluded that the study hours after school had a significant influence on the performance of students in mathematics, while no significant influence was established on the performance of students in English. Further, more study hours after school had a significantly greater influence on the students' performance in Mathematics than a medium level of study hours after school. The distance to school has a significant influence on the performance of students in mathematics. However, the performance of students in English was not influenced by the distance to school. Furthermore, shorter (low) and longer (high) levels of the travelling distance to school had a significant influence on the students' performance in mathematics. Conclusively, the findings revealed that study hours after school and the distance to school both have an influence on students' performance in mathematics, while students' performance in English was not influenced. 
It was recommended that policymakers and parents should ensure that the children stay closer to the school to avoid wasting time in travelling, enabling them to have more hours to study, particularly after school. The extra hours are necessary to improve the performance in mathematics. As there are only 33 senior secondary schools in Botswana, it is not always possible for a parent to select, and admit their child to, the school nearest to their home. Therefore, it was further recommended that new schools should be established in various strategic locations in the country to reduce the distance which students have to travel to school. Increasing the provision of hostel accommodation within the school campus is also recommended. Alternatively, school buses can be arranged for transporting students to and from schools to reduce the wastage of travelling time.

\section{References}

Akhtar, Z. (2012). Socio-economic status factors affecting the students' achievement: A predictive study. International Journal of Social Sciences and Education, 2(1), 281-287.

Al Shawwa, L., Abulaban, A. A., Abulaban, A. A., Merdad, A., Baghlaf, S., Algethami, A., \& Balkhoyor, A. (2015). Factors potentially influencing academic performance among medical students. Advances in Medical Education and Practice, 6, 65-75.Available at: https://doi.org/10.2147/amep.s69304.

Ali, K., Kiani, A., \& Ahmed, N. (2018). Determinants of students' performance in their studies in Pakistan. Journal of Research in Social Sciences, 6(1), 206-223.

Andersson, E., Malmberg, B., \& Osth, J. (2012). Travel-to-school distances in Sweden 2000-2006: Changing school geography with equality implications. Journal of Transport Geography, 23, 35-43.Available at: https://doi.org/10.1016/j.jtrangeo.2012.03.022.

Andre-Bechely, L. (2007). Finding space and managing distance: Public school choice in an urban California district. Urban Studies, 44(7), 1355-1376.Available at: https://doi.org/10.1080/00420980701302304.

Arubayi, E. (2005). Comparing average distance travelled to schools by students in primary and secondary schools in Delta and Edo States and its effect on attendance. DELSU Journal of Educational Research and Development, 4(1), 1-9.

Avong, H. N. (2013). Poor performance in mathematics among senior secondary school students in Kaduna state: What's to blame. Journal of Research in National Development, $11(2), 319-324$.

Barbarick, K., \& Ippolito, J. (2003). Does the number of hours studied affect exam performance? Journal of Natural Resources and Life Sciences Education, 32(1), 32-35.Available at: https://doi.org/10.2134/jnrlse.2003.0032.

Botswana Examinations Council. (2010). BGCSE examinations summary of results. Gaborone: Botswana Government Pinter.

Botswana Examinations Council. (2011). BGCSE examinations summary of results. Gaborone: Botswana Government Printer.

Botswana Examinations Council. (2015). BGCSE Examinations summary of results. Gaborone: Botswana Government Printer.

Botswana Examinations Council. (2016). BGCSE examinations summary of results. Gaborone: Botswana Government Printer.

Botswana Examinations Council. (2019). BGCSE examinations summary of results. Gaborone: Botswana Government Printer.

Bulawa, P. (2017). Academic performance - where we stand. Weekend Post, 1.

Burgess, S., Greaves, E., Vignoles, A., \& Wilson, D. (2009). Parental choice of primary school in England: What 'type' of school do parents choose? Working Paper No. 09/224, The Centre for Market and Public Organization, University of Bristol.

Camello, N. C. (2014). Factors affecting the engineering students' performance in the OBE assessment examination in mathematics. International Journal of Academic Research in Progressive Education and Development, 3(2), 87-103.Available at: https://doi.org/10.6007/ijarped/v3-i2/913.

Creswell, J. W., \& Creswell, J. D. (2017). Research design: Qualitative, quantitative, and mixed method approaches: Sage Publications.

Easton, S., \& Ferrari, E. (2015). Children's travel to school—the interaction of individual, neighbourhood and school factors. Transport Policy, 44, 9-18.Available at: https://doi.org/10.1016/j.tranpol.2015.05.023

Ebinum, U. S., Akamagune, N. E., \& Ugbong, B. I. (2017). The relationship between school distance and academic achievement of primary school pupils in Ovia North-East LGA, Edo State Nigeria. International Journal of Advanced Research and Publications, 1(5), 427-435.

Falch, T., Lujala, P., \& Strom, B. (2011). Geographical constraints and educational attainment. Working Paper Series No.9/2011. Retrieved from: http://www.svt.ntnu.no/iso/wp/2011/9_Geographical\%20constraints.pdf.

Getachew, B. (2018). Factors affecting student's academic performance in Ahuntegen general secondary school, North Wollo Zone, Ethiopia. Journal of Education and Learning (EduLearn), 12(2), 198-206.Available at: https://doi.org/10.11591/edulearn.v 12i2.8404.

Government of Botswana. (2015). Whole school inspection Report, molefi senior secondary school. Gaborone: Kgatleng Education Region. Ministry of Basic Education.

Hallo, M. D., Tixi Torres, D., Piñas, L. F., \& Zhining, C. J. E. (2020). Relationship between study and sleep hours with the academic performance of university students. Contemporary Dilemmas: Education, Policy and Values, 7(2), 1-14.

He, S. Y., \& Giuliano, G. (2018). School choice: Understanding the trade-off between travel distance and school quality. Transportation, 45(5), $1475-1498$.

Hinchson, E. A., McGrath, L., Hopkins, W., Oliver, M., Badland, H., Mavoa, S., \& Kearns, R. A. (2014). Distance to school is associated with sedentary time in children: Findings from the URBAN study. Frontiers in Public Health, 2(151), 1-8.

Idowu, O. O. (2016). An investigation of mathematics performance of high school students in lagos state, Nigeria: External factors. Urban Education Research \& Policy Annuals, 4(1), 178-188.

Krohn, G. A., \& O'Connor, C. M. (2005). Student effort and performance over the semester. The Journal of Economic Education, 36(1), 328.Available at: https://doi.org/10.3200/jece.36.1.3-28.

Lahmers, A. G., \& Zulauf, C. (2000). The secret to academic success: Hours and hours of study. Journal of College Student Development, 41 (5), $545-554$.

Ledwith, V. (2009). Open enrolment and student sorting in public schools: Evidence from Los Angeles County. Environment and Planning A, 41(5), 1109-1128.Available at: https://doi.org/10.1068/a4128.

Mandic, S., Sandretto, S., Bengoechea, E. G., Hopkins, D., Moore, A., Rodda, J., \& Wilson, G. (2017). Enrolling in the closest school or not? Implications of school choice decisions for active transport to school. Journal of Transport \& Health, 6, 347-357.

Marique, A.-F., Dujardin, S., Teller, J., \& Reiter, S. (2013). School commuting: The relationship between energy consumption and urban form. Journal of Transport Geography, 26, 1-11.Available at: https://doi.org/10.1016/j.jtrangeo.2012.07.009.

Mhiliwa, J. A. (2015). The effects of school distance on students' academic performance: A case of community secondary schools in Makambako Town Council. Doctoral Dissertation, The Open University of Tanzania.

MoESD Ministry of Education and Skills Development. (2015). National education for all (EFA 2015) review: Botswana Country Report. Gaborone, Botswana: Botswana Government.

Moyo, W. (2013). Causes and effects of poverty on academic achievements of rural secondary school students: Case of Tshazi secondary school in Insiza District. International Journal of Asian Social Science, 3(10), 2 104-2113.

Nelson, D., Misra, K., Sype, G. E., \& Mackie, W. (2016). An analysis of the relationship between distance from campus and GPA of commuter students. Journal of International Education Research, 12(1), 37-46.Available at: https://doi.org/10.19030/jier.v 12i1.9565.

$\mathrm{Ng}$, S. F., Zakaria, R., Lai, S. M., \& Confessore, G. J. (2016). A study of time use and academic achievement among secondary-school students in the state of Kelantan, Malaysia. International Journal of Adolescence and Touth, 21(4), 433-448.Available at: https://doi.org/10.1080/02673843.2013.862733.

Nonis, S. A., \& Hudson, G. I. (2010). Performance of college students: Impact of study time and study habits. Journal of Education for Business, 85(4), 229-238.Available at: https://doi.org/10.1080/08832320903449550.

Nyroos, M., Jonsson, B., Korhonen, J., \& Eklöf, H. (2015). Children's mathematical achievement and how it relates to working memory, test anxiety and self-regulation: A person-centred approach. Education Inquiry, 6(1), 26026.Available at: https://doi.org/10.3402/edui.v6.26026. 
Oketch, M. (2017). Cross-country comparison of TVET systems, practices and policies, and employability of youth in Sub-Saharan Africa1. Vocational Education and Training in Sub-Saharan Africa, 25-38.

Onderi, H., Kiplangat, R. K., \& Awino, J. (2014). Factors contributing to poor academic performance in Kenya certificate of secondary education in public secondary schools in Kericho Sub-county, Kericho County, Kenya. Kenyan Journal of Educational Planning, Economic and Management, 7(2), 1-14.

Piza, C., Alexis, I., Galarza, P., J. L., Barahona, T., L. I., \& Nivela, Z. W. V. (2019). Estimation of the level of influence and impact that study hours and self-esteem have on the academic performance of the students of the regional autonomous University of the Andes. Babahoyo headquarters. Contemporary Dilemmas: Education, Politics and Values, 7(1), 1-16.

Pradhan, R. K., \& Sinha, N. (2017). Impact of commuting distance and school timing on sleep of school students. Sleep and Biological Rhythms, 15(2), 153-158.Available at: https://doi.org/10.1007/s41105-017-0091-0.

Rodríguez Tapia, C., Caguanco Almeida, G., Portilla, S. R., \& Coca Freire, D. (2019). Analysis of the incidence on the academic performance of the scholarship students taking into account the hours of study and the qualifications of a group of the Autonomous Regional University of the Andes. Contemporary Dilemmas: Education, Policy and Values, 7(1), 1-17.Available at: https://doi.org/10.46377/dilemas.v28i1.1666.

Silva, M. O. F., Hidalgo, R., M. R., Garcés, M., D. V., \& Riofrio, M. C. A. (2019). Determination of the extent to which the hours spent studying and the hours spent sleeping determine the academic performance of students. Contemporary Dilemmas: Education, Politics and Values, $7(1)$.

Taiwo, O. R. (2019). Impact sf school plants planning on primary school pupils ' academic performance. International Journal of Advanced Academic Research | Arts, Humanities and Education, 5(9), 83-90.

Thapa, A. (2015). Public and private school performance in Nepal: an analysis using the SLC examination. Education Economics, 23(1), 4762.Available at: https://doi.org/10.1080/09645292.2012.738809.

The New Times. (2016). Rwanda's Leading daily (6th July 2016). Performance: Why distance to school matters. 1.

Thomas, C. A. (2016). Going the distance!: How distance to school relates to student education outcomes. Doctoral Dissertation, University of California, Los Angeles.

Umameh, M. A. (2011). A survey of factors responsible for students' poor performance in mathematics in senior secondary school certificate examination (ssce) in Idah local government area of Kogi state, Nigeria. Unpublished M. Ed Thesis, University of Benin, Benin City.

UNESCO. (2015). Education for all national review Report. Gaborone: Government Printers.

Vuri, D. (2007). The effects of availability and distance from school on children's time allocation in Ghana and Guatemala. Working Paper May 2007, Understanding Children Work (UCW) Project, University of Rome, Rome Tor Vergata.

Warrington, M. (2005). Mirage in the desert? Access to educational opportunities in an area of social exclusion. Antipode, 37(4), 796816.Available at: https://doi.org/10.1111/j.0066-4812.2005.00526.x.

Waswa, A. W. (2015). Factors affecting girl-child progression rates in primary schools in ASAL areas: A survey of West Pokot Sub County in West Pokot county Kenya. Doctoral Dissertation, Moi University.

Wells, A. S., Warner, M., \& Grzesikowski, C. (2013). The story of meaningful school choice: Lessons from interdistrict transfer plans. In G. Orfield, E. Frankenberg \& associates (Eds.), Educational delusions?: Why choice can deepen inequality and how to make schools fair (pp. 187-218). Oakland: University of California Press.

Yemi, T. M., \& Adeshina, A. N. G. (2013). Factors influencing effective learning of mathematics at senior secondary schools within Gombe Metropolis, Gombe State Nigeria. International Institute for Science, Technology and Education, 4(21), 61-66.

Zahyah, H. (2008). The relationship between aspects of socio-economic factors and academic achievement. Malaysian Education Journal, 33(2208), 95-105. 